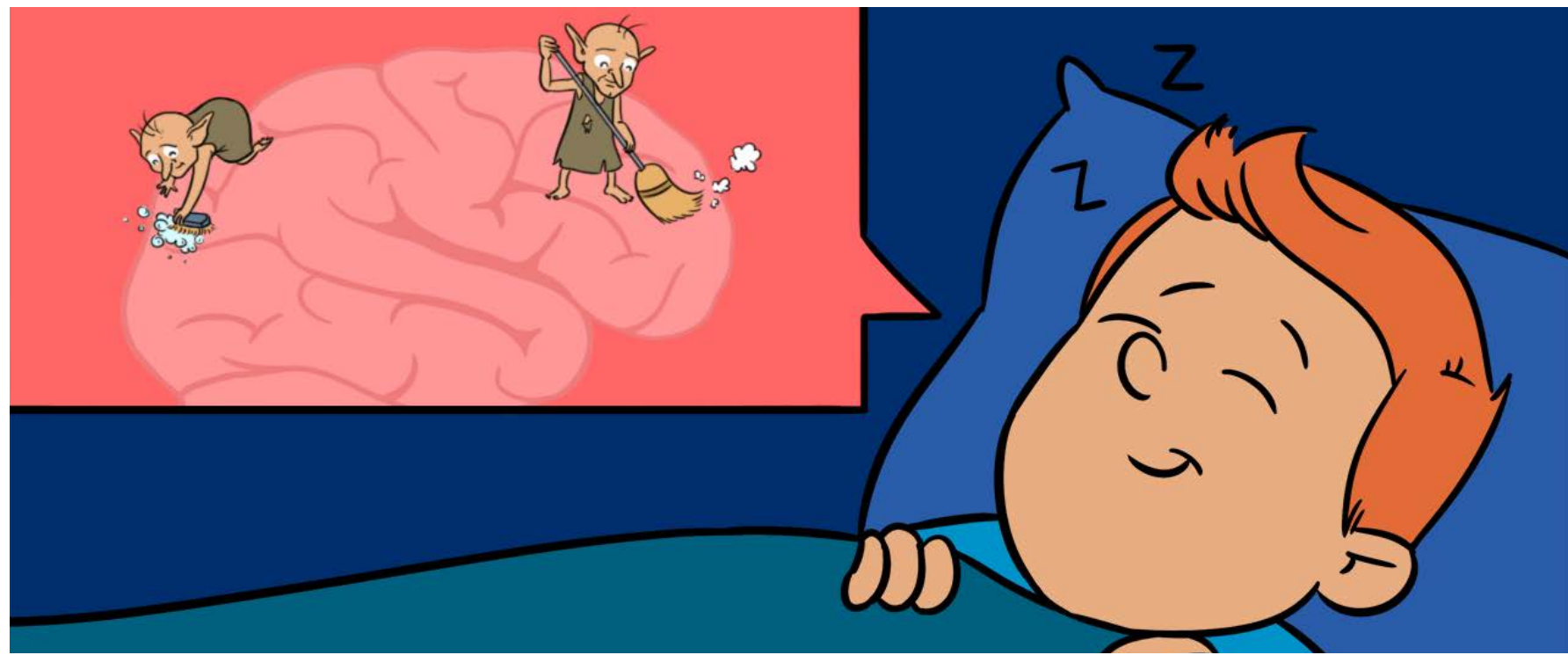

\title{
DO HOUSE-ELVES CLEAN YOUR BRAIN WHILE
}

\section{YOU SLEEP?}

\section{Ken A. Paller*}

Department of Psychology, Northwestern University, Evanston, IL, United States

\section{REVIEWED BY:

EXPLORA
SCIENCE
CENTER AND
CHILDREN'S
MUSEUM
AGE: 7-15

NEUROSCIENTISTS

Scientists who study brains and nervous systems.
Sleep will consume one-third of your life. You can't avoid it, nor should you. Sound slumber can make you feel wonderful. But there's more to it. Sleep is also essential for learning. Much of who you are-your memories and your habits - may depend on what your brain does while you sleep. This article covers some new experiments on this topic, and some unexpected findings. Each day, you acquire all sorts of new knowledge. That includes things you read, things you learn in school, news about friends, and your own creative thoughts or pictures. And maybe where you put down that book you were reading. Later, many of these memories can be difficult to remember. Recent scientific findings are helping us understand how brain activity during sleep aids remembering.

The brain is far from idle when we sleep. No one knows exactly why. Put a computer to sleep, and it simply stops and does nothing. Not our brains. Yet, we wake up knowing very little about what our brains have been doing.

Neuroscientists have many ways to observe brain activity. And they have conjured up many explanations for these mysterious goings-on inside the sleeping brain. 
Here's one idea. Picture a house-elf, busy the whole night, just like in Harry Potter's world. The author J. K. Rowling portrayed the house-elf as a creature who worked like a slave in the house of a wizard, each night invisibly cleaning up the mess the wizard made during the day. But this "house-elf-of-the-brain" would instead work to strengthen valuable memories and squash unimportant ones. Can you imagine a group of miniature house-elves organizing memories in your brain in this way? Perhaps that's how memories end up in good working order the next morning.

Yes, that's a fantasy, not neuroscience. But our brains face a big challenge. We need to hold on to important memories, and for that to happen, it helps to forget the unimportant ones. So, something like magic is needed to make learning succeed.

Each day, countless memories are stored in your brain. Before long, they may all be forgotten. Pick a day from the middle of last week. How much can you remember about that day right now? Chances are, most of the memories you created that day have already disappeared (or as Harry Potter might say, "disapparated").

What if you want to counteract this memory loss? You already know what to do! You practice what you've learned. It's the same thing actors do when they rehearse their lines in a play.

When you want to memorize something, bring it to mind and rehearse it, repeatedly.

COGNITIVE

NEUROSCIENCE

That part of neuroscience engaged with investigating mental functions.

\section{BRAIN NETWORKS}

A set of brain cells (neurons) that can be active together. Learning involves changes in such brain networks. Neuroscientists use the term "neural plasticity" to refer to these changes in how neurons in a network are connected with each other.
One of the big challenges in Cognitive Neuroscience is to explain how new information gets into your brain. We are also investigating how rehearsal helps. The effort you spend working to remember pays off. The reason is that brain networks change when you use them. So, when you remember something, that memory gets stronger.

But that's not the only way to select memories to strengthen. It also happens while we sleep. We don't need to plan to rehearse memories during sleep. We do so naturally, and we wake up with no awareness of doing so.

\section{LISTEN FOR THE TONE}

A recent scientific breakthrough helped connect memory and sleep. It involved a series of experiments with sounds. If a flute plays a soft tone while a person is learning a fact, the sound and the fact can be linked. Later, during sleep, that flute sound can be soft enough to not awaken the person but still remind them of the fact. When this happens, the brain networks involved in remembering the fact change. 
Most scientists studying sleep used to think that hearing didn't work very well during sleep. That view wasn't quite right. In 2009, my students and I discovered that soft sounds could be used to investigate memory rehearsal during sleep [1]. We concluded that the sounds worked as "memory reminders," because they changed the storage of recent memories.

Scientists working in several different countries have now repeated this type of experiment many times [2]. Usually, students play a key role. In our experiment, students first learned where 50 pictures appeared on a computer screen. For example, they might see a flute in the upper left corner and a stapler in the lower right. Each picture appeared together with a specific sound. This learning was not much fun compared to playing a video game, but the students cooperated anyway and learned all the locations. Next, each student took a nap. After they woke up, we tested them to see what they remembered. They had to recall exactly where they had seen each picture. We measured where they placed it on the screen. The closer they placed each picture to the spot where it belonged, the better they scored on this memory test.

For some of the pictures, the specific sounds that came with them were played during the nap. The students slept right through this. They didn't know that any sounds were played.

We compared recall for those pictures and the remaining pictures (for which the sound was not played during sleep). Recall was better for pictures when their sounds were played during sleep. When the sounds played, memory storage in the brain must have changed (see Video 1). This general experimental procedure (see Figure 1) thus allows neuroscientists to hack into memories.

\section{VIDEO 1}

Targeted Memory

Reactivation. This video segment was produced through the National Science Foundation and their Science Nation team. http://www.nsf.gov/news/ special_reports/science_ nation/sleepmemory.jsp

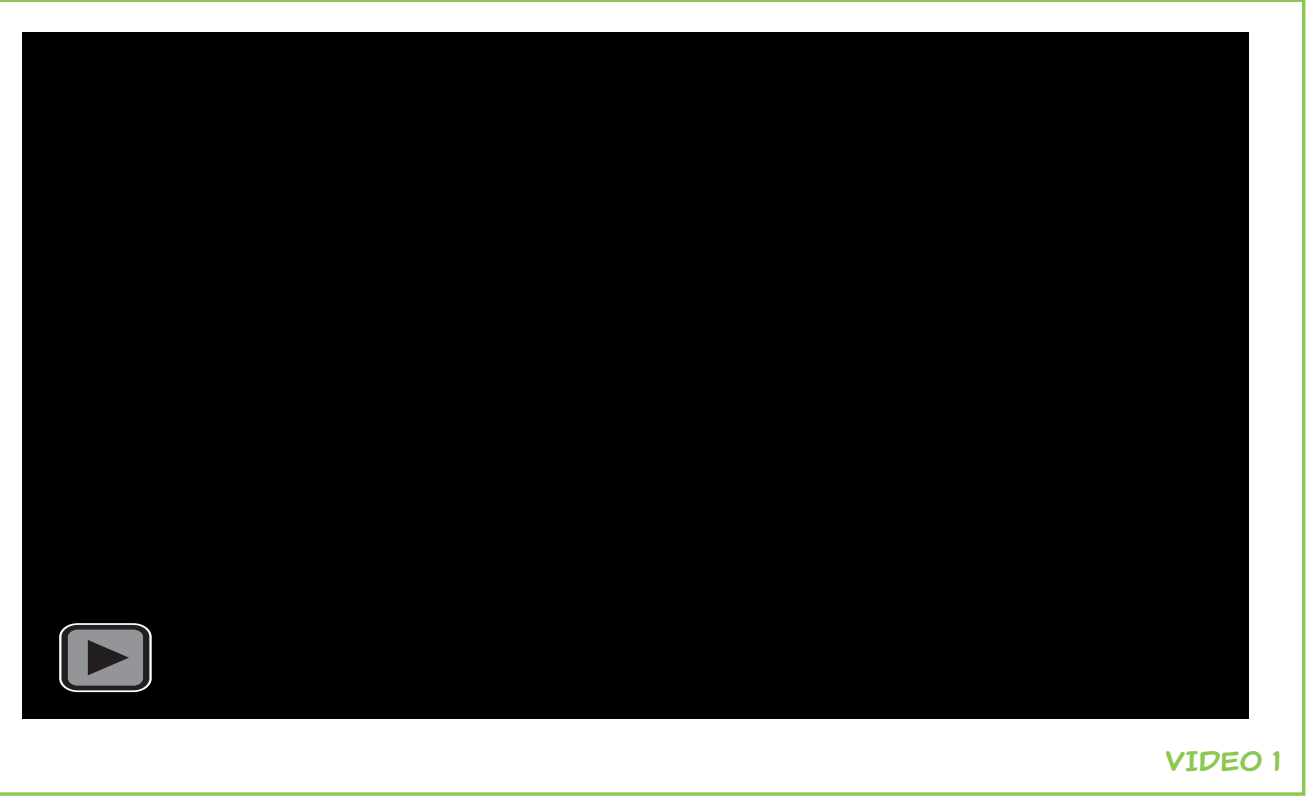




\section{FIGURE 1}

The experiments described here typically have three parts. First, people learn some new information. The new information can be from a book, or it could be about where objects are located, what foreign words mean, or how to perform a piece of music. Second, during sleep, that information may be reactivated so that it is stored in the brain more effectively. A sound of a bell, for example, can remind the sleeping brain of information from a book, if the bell was also ringing during learning. Similarly, a smell can be present when learning is accomplished, and then presented again during sleep. Memory reminders during sleep increase the likelihood that the information is firmly memorized. In the third part of the experiment, there is a memory test. Remembering is improved for information that was reactivated. These experiments help us to understand the normal process of learning. It seems that when we sleep every night, our brains are busy practicing and recalling the new things we've learned. Of course, it is also helpful to rehearse memories when we are awake. Why memory rehearsal might be particularly helpful during sleep is presently unclear, although the brain produces intriguing electrical signals that seem to hint at what's going on inside. These and other mysteries are waiting to be solved by the neuroscientists of the future.

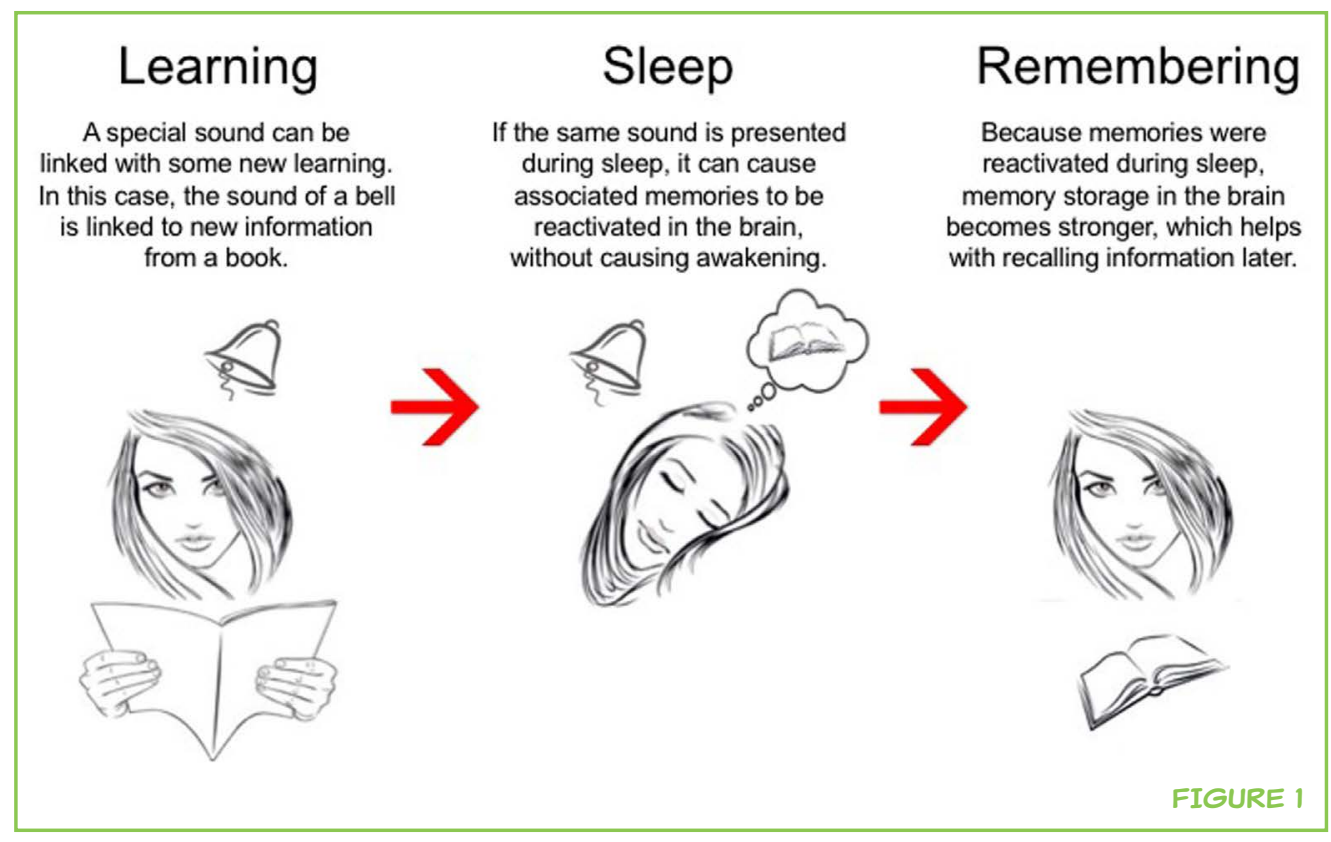

\section{MEMORY HACKING}

This research moves us forward in understanding how memories are stored in the brain. The findings also raise a wild possibility. Maybe people could select memories to reactivate while sleeping at home. Why do this? One reason is that we may not get enough sleep. And even when we do, sleep may not work perfectly. We may unknowingly rehearse things wed prefer to forget. Is your sleep filled with any annoying memories? Perhaps you could rehearse what you really want to remember instead.

There are many possibilities for using sleep to improve learning. In 2015, researchers helped students to learn a foreign language using the same basic method [3]. Students first spent some time learning Dutch words. Some of those words were presented again later, when the students were asleep. When they woke, they knew the meanings of the words presented while they were asleep better than for those not presented while they were asleep. In a similar study, we improved the learning of rules of grammar important for learning a new language [4]. We also strengthened musical skills during sleep [5]. In that study, students first learned to perform two songs on a keyboard. It was like the Guitar Hero videogame: moving circles guided the students to press keys in the proper way to produce each song. Then came a nap. Afterward, the students were better at playing the song that had been quietly presented to them while they slept.

We learn some skills and habits without knowing that we are learning them. The technical term for this type of learning is implicit learning. One example is the bad habit of teeth grinding during sleep. If you do that, how can you learn to stop? It can be difficult to control what you only do while you are sleeping. 
IMPLICIT

LEARNING

A type of learning that happens without people realizing what they have learned. After this learning, as in gaining a skill, habit, or procedure, people may think and behave differently without realizing that their thoughts and behaviors have been changed by implicit learning.

\section{UNCONSCIOUS} SOCIAL BIAS

A kind of habit learning in which we acquire general ideas about groups of people. These biases then influence how we treat others, sometimes unfairly, and even when we don't realize that our behaviors are governed by this learning.
Our idea is that special sounds played during sleep might help. First, people would learn to release their jaws when hearing the "relax sound" during the day. That same sound could then cue them to relax the jaw during sleep.

New ideas like this need to be tested. We don't know yet whether they will work. But we are hopeful because of various other experimental results. For example, our sleep method helped with another habit when we used it to reinforce training to reduce prejudice [6].

To understand our experiment, consider the following. We all gradually pick up general beliefs about groups of people from exposure to movies, TV, and the like. This is a natural part of learning. We can pick up such ideas (generalizations) without knowing it, and even without agreeing with the ideas. The ideas can then influence our thoughts and behaviors toward people in those groups. Here's one specific example. Long ago, a common stereotype was that women were not smart enough to be scientists. Scientists in movies and on TV were often played by actors who were old, bald, white men. Exposure to that stereotype can produce an unconscious social bias. This type of bias about a group of people regularly influences how we treat other people, and we needn't be aware of this influence. But like other types of learning, these habits of bias can be changed by training. For example, the repeated experience of meeting women who are amazing scientists can reduce the bias you might get from the media. Our experiment showed that memory reminders during sleep can reinforce training to reduce common biases about people.

Research might also produce ways to achieve other valuable benefits using memory reminders during sleep. For example, learning can be really important after someone suffers brain damage. The patient may need to recover the ability to speak or to move normally. Rehabilitation sessions aim to speed learning in certain brain networks. Recovery depends on how well this learning progresses. With only a few hours of therapy a week, it can take a while for this rehabilitation to work. Sleep-assisted therapy could use sounds associated with the actions the patient is trying to learn. Playing those sounds nightly might speed the person's recovery. Future experiments will hopefully show how to make this work.

\section{CAN MEMORY HACKING BE HARMFUL?}

New ways to modify memories could have a cost. So far, I've emphasized ways to help people. But could these methods also harm people?

The author Aldous Huxley imagined how bad things could go in his novel, Brave New World [7]. In this story, the state controlled its citizens through what Huxley called "hypnopedia." That is, when infants and children slept, they were taught certain ways to think. Everyone was assigned a specific role in society, some high and some low. And they were all persuaded to 
buy things and be eager consumers. Because of their training, people in this world seemed to have no choice but to take on their duties and to accept their assigned status.

We should proceed carefully with new technology. People do not want their memories to be altered during sleep without their permission. Abuse of this method might be possible. For example, an unethical hotel owner could play messages to hotel guests while they sleep. The guests might receive unwanted advertising without even knowing it. We need to be watchful so methods for changing memories during sleep are not abused.

In the experiments I've described, the procedure required some training. People were always awake during this training and what they learned wasn't hidden from them. One way for a person to avoid unwanted memory changes during sleep is to exercise the option to reject what is being taught in the first place.

Neuroscience has opened the door to new possibilities for guiding the sleeping brain to work better. In a sense, it's as if house-elves really do clean your brain while you sleep. With further scientific efforts in these new directions, a better understanding of the sleeping brain could bring many different benefits. Ideally, this research will give us more reasons to treasure-rather than resent-our need for sleep.

\section{ACKNOWLEDGMENTS}

Some of the research leading to these results received funding from the National Science Foundation. I am grateful to my many collaborators in this research, and to my friends Marcia Grabowecky, John Kounios, and Lisa Munoz for their help with the writing. This article is based on an article that originally appeared on LiveScience.com.

\section{REFERENCES}

1. Rudoy, J. D., Voss, J. L., Westerberg, C. E., and Paller, K. A. 2009. Strengthening individual memories by reactivating them during sleep. Science 326:1079. doi:10.1126/science.1179013

2. Oudiette, D., and Paller, K. A. 2013. Upgrading the sleeping brain with targeted memory reactivation. Trends Cogn. Sci. 13:142-9. doi:10.1016/j.tics.2013. 01.006

3. Schreiner, T., and Rasch, B. 2015. Boosting vocabulary learning by verbal cueing during sleep. Cereb. Cortex 25:4169-79. doi:10.1093/cercor/bhu139

4. Batterink, L. J., and Paller, K. A. 2017. Sleep-based memory processing facilitates grammatical generalization: Evidence from targeted memory reactivation. Brain Lang. 167:83-93. doi:10.1016/j.bandl.2015.09.003 
5. Antony, J. W., Gobel, E. W., O'Hare, J. K., Reber, P. J., and Paller, K. A. 2012. Cued memory reactivation during sleep influences skill learning. Nat. Neurosci. 15:1114-6. doi:10.1038/nn.3152

6. Hu, X., Antony, J. W., Creery, J. D., Vargas, I. M., Bodenhausen, G. V., and Paller, K. A. 2015. Unlearning implicit social biases during sleep. Science 348:1013-5. doi:10.1126/ science.aaa3841

7. Huxley, A. 1932. Brave New World.

SUBMITTED: 12 December 2017; ACCEPTED: 11 May 2018;

PUBLISHED ONLINE: 22 June 2018.

EDITED BY: Kathleen Haaland, University of New Mexico, United States

CITATION: Paller KA (2018) Do House-Elves Clean Your Brain While You Sleep? Front. Young Minds 6:23. doi:10.3389/frym.2018.00023

CONFLICT OF INTEREST STATEMENT: The authors declare that the research was conducted in the absence of any commercial or financial relationships that could be construed as a potential conflict of interest.

COPYRIGHT ( 2018 Paller. This is an open-access article distributed under the terms of the Creative Commons Attribution License (CC BY). The use, distribution or reproduction in other forums is permitted, provided the original author(s) and the copyright owner are credited and that the original publication in this journal is cited, in accordance with accepted academic practice. No use, distribution or reproduction is permitted which does not comply with these terms.

\section{REVIEWED BY}

EXPLORA SCIENCE CENTER AND CHILDREN'S MUSEUM, AGE: 7-15

The Explora Young Minds reviewers are a group of science enthusiasts working with museum educators and mentors from the University of New Mexico. We enjoy learning about the brain through the articles and hands-on activities and demonstrations. We also enjoy reading about new research, asking questions, and making suggestions to help the scientists make their work more understandable for everyone!

\section{AUTHOR}

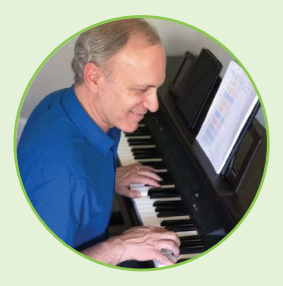

\section{KEN A. PALLER}

I am a professor at Northwestern University, which is next to Lake Michigan in Evanston, IL, USA. I enjoy the challenge of designing experiments that can provide insights into memory and our conscious experiences. I also enjoy my hobby of playing in a rock-and-roll band. I feel very fortunate that my day job involves wondering about how human minds work. I'm hopeful that our collective efforts to gain neuroscientific knowledge will contribute to improving people’s lives. *kap@northwestern.edu. 